\title{
Patrimônios da cidade de São Paulo na contística do início do século XX
}

Marilúcia Mendes Ramos

Universidade Federal de Goiás

RESUMO: ESTABELECE-SE PARA ANÁLISE DA REPRESENTAÇÃO DA URBANIZAÇÃO DA CIDADE DE SÃO PAULO O PERÍODO QUE COMPREENDE AS PRIMEIRAS DÉCADAS DO SÉCULO XX, ÉPOCA ABORDADA EM CONTOS PUBLICADOS NAS DÉCADAS DE 20, COMO "O FISCO", DE MONTEIRO LOBATO, E "ARMAZÉM PROGRESSO SÃO PAULO", DE ALCÂNTARA MACHADO, COMO TAMBÉM NA DÉCADA DE 40, "PRIMEIRO DE MAIO", DE MÁRIO DE ANDRADE. A ÉPOCA ABORDADA NOS CONTOS COMPREENDE A FASE LITERÁRIA DO MODERNISMO BRASILEIRO E SEUS DESDOBRAMENTOS, QUE SURGE ENTRE NÓS COMO UMA ARTE DA CIDADE, POIS A URBE REPRESENTAVA O QUE HAVIA DE FUTURISMO, DE AVANÇO TECNOLÓGICO, DE MOVIMENTO E DE DESCOBERTA DO BRASIL. A UNIR OS TRÊS, SEUS PATRIMÔNIOS MÓVEIS, IMÓVEIS E IMATERIAIS.

ABSTRACT: IT IS ESTABLISHED TO THE ANALYSIS OF THE REPRESENTATION OF THE URBANIZATION OF SÃO PAULO CITY THE PERIOD BETWEEN THE FIRST DECADES OF THE 2OTH CENTURY, A TIME WHICH IS APPROACHED IN SHORT STORIES PUBLISHED IN THE 1920S, SUCH AS "O FISCO", BY MONTEIRO LOBATO, AND "ARMAZÉM PROGRESSO SÃO PAULO", BY ALCÂNTARA MACHADO, AS WELL AS IN THE 1940S, "PRIMEIRO DE MAIO", BY MÁRIO DE ANDRADE. THE EPOCH ALLUDED IN THESE SHORT STORIES COMPREHENDS THE LITERARY PERIOD OF THE BRAZILIAN MODERNISM AND ITS UNFOLDING, WHICH EMERGES TO US AS AN ART OF THE CITY BECAUSE THE TOWN REPRESENTED THE FUTURISM, THE TECHNOLOGICAL ADVANCE, THE MOVEMENT AND THE DISCOVERY OF BRAZIL. BONDING THESE THREE SHORT STORIES, ITS MOVEABLE, UNMOVABLE AND IMMATERIAL PATRIMONY.

PALAVRAS-CHAVE: CONTOS, SÉCULO XX, CIDADE DE SÃO PAULO, PATRIMÔNIOS. KEYWORDS: SHORT STORIES, 2OTH CENTURY, SÃO PAULO CITY, PATRIMONIES. 
representação literária da cidade constrói-se pelos discursos dos que a observam e elegem como matéria ficcional, permitindo aos leitores de outras épocas, além daquela do presente da enunciação, reconstruir a ambiência desses discursos, tanto no que toca ao espaço eleito como cenário para as ações, como às personagens escolhidas para essa representação. As escolhas do escritor, baseadas no que experienciou em determinado contexto, estarão presentes no texto artisticamente produzido e repercutirão no leitor. Tal processo foi assim abordado por Cortázar em seu texto "Alguns aspectos do conto": o contista e o fotógrafo têm de "escolher e limitar uma imagem ou um acontecimento que sejam significativos, que não só valham por si mesmos, mas também sejam capazes de atuar no espectador ou no leitor como uma espécie de abertura, de fermento que projete a inteligência e a sensibilidade em direção a algo que vai muito além do argumento visual ou literário contido na foto ou no conto" (1974, p. 151-152. Grifos do autor). Assim, autores como Monteiro Lobato, Alcântara Machado e Mário de Andrade escolhem acontecimentos significativos, os selecionam, tais escolhas agem nos leitores de todas as épocas e projeta a sensibilidade desse leitor para algo ali tratado, o que permite a apreensão da sensibilidade do olhar do escritor para a realidade que o envolve e da qual é parte - aqui a cidade de São Paulo - assim como para as suas representações literárias.

O pensamento de Marx auxilia no entendimento do processo de escolha das representações. $\mathrm{O}$ autor argumenta, refletindo sobre a sensibilidade, que o homem é o único animal em que os sentidos são produtos de uma história social e cultural, especialmente de uma história das diversas artes nas suas especificidades, cada qual atuando em seu domínio próprio. As artes da linguagem serviriam então, cada qual em seu setor, para exprimir alguns planos da realidade humana, dando-lhes uma forma literária. Assim, a educação ou a informação dos cinco sentidos representaria a obra de toda a história do mundo até hoje. Ainda em "Manuscritos econômicos e filosóficos" (1968), Marx afirma que todas as relações humanas com o mundo (ver, ouvir, cheirar, ter paladar, tato, pensar, olhar, sentir, querer, agir, amar, em suma, todas as dimensões da individualidade do ser humano) são, na sua realidade objetiva -, ou no seu comportamento diante do objeto -, a apropriação desse objeto (1968, p. 119-120). E tem sido pelo desenvolvimento objetivo do ser humano que a riqueza dos sentidos humanos subjetivos (um ouvido musical, um olho 
sensível à beleza das formas), que os sentidos capacitados aos prazeres humanos, têm se transformado em sentidos que se manifestam como forças do ser humano e que são ou desenvolvidos ou produzidos. As relações humanas com o mundo, neste caso do escritor com o mundo, como ver, pensar e agir permitem a apropriação do objeto - a cidade de São Paulo - e sua representação de acordo com a sensibilidade de quem observa.

Também o pensamento de Bergson, em Matéria e memória (1990, p. 57), contribui para se entender que a memória permitiria a relação do corpo presente com o passado e interferiria nas representações e, pela memória, o passado seria presentificado, misturando-se às percepções imediatas, que também seriam deslocadas, indo formar a consciência. Tais argumentos são fundamentais para a sondagem da representação da cidade de São Paulo nos três contos, pois se Lobato recorre às origens para entender o seu presente, nós leitores de hoje recorremos às suas representações, bem como às dos outros contistas, para ampliar a história da formação e desenvolvimento da cidade.

As reflexões de Marx e Bergson propiciam bases para se pensar as representações da cidade de São Paulo pelos contistas, nos quais a urbe está vibrante, é mais que memória, está presentificada e, na leitura dos escritores, passa a ser imagem, mas feita de gente, sobretudo dos que vivem à margem.

A representação da cidade pela literatura, ou pela história ou arquitetura, pode reconstituir o imaginário de um espaço que, até mesmo, já não exista mais, mas que foi germe para a cidade como se configura hoje. Embora o espaço num texto literário seja fictício, no século XX acompanha-se a reelaboração dessa categoria literária, que passa de cenário para as ações a quase personagem nos textos contemporâneos e hoje o urbano é espaço preferencial. O escritor vivenciou transformações na urbe que o levaram a fazer escolhas temáticas, a registrar, a informar, a levar para o texto ficcional personagens e fatos do mundo real.

Estabelece-se para a análise da representação da urbanização da cidade de São Paulo o período que compreende as primeiras décadas do século XX, época abordada em contos publicados nas décadas de 20 , como "O fisco", de Monteiro Lobato (1993), e "Armazém Progresso de São Paulo”, de Alcântara Machado (1996), como também na de 40, "Primeiro de Maio", de Mário de Andrade (1980). A época abordada nos contos compreende a fase literária do Modernismo brasileiro e seus desdobramentos, que surge entre nós como 
uma arte da cidade, pois a urbe representava o que havia de "futurismo", de avanço tecnológico, de movimento e de redescoberta do Brasil. A unir os três, seus patrimônios móveis, imóveis e imateriais (hábitos, costumes e o mundo do trabalho, mas visto pelo baixo e invisível), pois na leitura de cada escritor foram selecionadas personagens e situações peculiares dentro da grande cidade que, observadas pelo micro, podem ser a própria imagem do macrocosmo.

Na década de 20 do século passado surgem os primeiros projetos preservacionistas de nossos patrimônios. Com a Revolução de 30 e o governo Varguista, visando assegurar que os bens representativos da história nacional não deixassem o país e nem fossem destruídas obras monumentais na urbanização da cidade, começam a ser criados instrumentos legais de preservação. A partir de 1935, com a criação do Departamento Municipal de Cultura da cidade de São Paulo, sob a direção de Mário de Andrade, anteprojetos de lei de proteção ao patrimônio cultural serão redigidos. Mário percebe a riqueza das expressões e manifestações culturais, a variedade cultural brasileira. Entretanto, sua concepção de patrimônio está muito adiante de seu tempo e quando Vargas cria o Instituto Jurídico do Tombamento pelo Decreto-Lei n. 25/1937 e o Serviço do Patrimônio Histórico e Artístico Nacional (SPHAN), são contemplados apenas bens móveis e imóveis, não se incluindo bens de natureza imaterial ou saberes e manifestações. As contribuições de Mário, conhecedor da vastidão cultural brasileira, só serão contempladas no final do século XX pelo Decreto n. 3551/2000, quando se institui o Registro de Bens Culturais de Natureza Imaterial, com mais quatro livros (Livro: do Registro dos Saberes, das Celebrações, das Formas de Expressão e do Registro dos Lugares) além dos quatro de 1937.

O assíduo pesquisador Mário de Andrade vale-se do espaço do texto literário para divulgar os patrimônios imateriais de sua cidade e os dois contistas seus contemporâneos também registrarão os "saberes" enraizados no cotidiano, como estabelecido pelo decreto de 2000(!), as "celebrações" (rituais e festas que marcam a vivência coletiva do trabalho, da religiosidade, do entretenimento e de outras práticas da vida social), as "formas de expressão" (manifestações literárias, musicais, plásticas, cênicas e lúdicas) e os "lugares" (mercados, feiras, santuários, praças e demais espaços onde se encontram e reproduzem práticas culturais coletivas), como se demonstrará adiante.

Os contos selecionados tratam de uma impressão construída literariamente no presente da enunciação, afetada pela memória do escritor, o qual traz para 
o seu presente dados que, analisados hoje, tornam-se memória viva de uma época que derivou no nosso presente. Nesse ir e vir, signos da vida precária, da pobreza, das diversões possíveis, das relações humanas e sociais, do mundo do trabalho, da culinária, do "antes" e do "agora", é que se vão enunciando, permitindo perceber o estabelecimento de relações afetivas com o espaço.

No início do século XX, antes da Semana de 1922, Monteiro Lobato publica três livros de contos, Urupês, de 1918; Cidades Mortas, de 1919 (cujo título alude às cidades do Vale do Paraíba que ficaram fora das linhas férreas construídas de 1869-1877, E. F. do Norte e E. F. D. Pedro II, que ligaram comercialmente cidades de São Paulo e Rio de Janeiro); e Negrinha, de 1920, os quais enfocam diversos problemas sociais brasileiros, principalmente referentes às mudanças pelas quais o Brasil passava do século XIX para o XX.

No conto "O fisco. Conto de natal", de Negrinha (1993), Lobato observa as transformações da urbe no seu presente e registra suas impressões sobre as rápidas mudanças a que assiste e sobre as quais atua também como agente transformador, posto que o habitante da urbe é, concomitantemente, vítima e agente das mudanças. Já no "Prólogo", cuja primeira frase nos remete à forma encontrada em Gênesis - "No princípio era o pântano...", visto já transformado no moderno Parque do Anhangabaú - as imagens do antes e do "agora" remetem o narrador à imagem da cidade como um organismo vivo, onde as ruas são como artérias "os passantes, o sangue. O desordeiro, o bêbado, o gatuno são os micróbios maléficos, perturbadores do ritmo circulatório. O soldado de polícia é o glóbulo branco - o fagócito de Metchenikoff" (LOBATO, 1993, p. 103).

Na parte seguinte, "O Brás", de novo o leitor é remetido à ideia de que tudo que há teve uma origem: “Também lá, no princípio era o charco”. As primeiras linhas mostram uma São Paulo a crescer vertiginosamente do centro para a periferia e um dos seus mais conhecidos patrimônios imóveis e marco de sua história de crescimento vertiginoso, o Viaduto do Chá, é descrito com o entusiasmo dos modernistas, de modo que o monumento construído acima do Vale do Anhangabaú e seu idealizador são reverenciados: "Que arrojo de homem, o Jules Martin que construíra aquilo!” (1993, p. 115).

Ao lado da pujança do patrimônio imóvel, o narrador volta seu olhar para o que viria a ser chamado de patrimônio imaterial da cidade, a gente que ajudou a erguer tudo "aquilo" e percebe a formação da desigualdade das classes sociais. A cidade de São Paulo é o local da contradição, desde o espaço físico: 
"Enquanto São Paulo crescia o Brás coaxava", sendo o Brás descrito como um lugar muito distante do centro e da modernidade da urbe; até a ocupação desse espaço da margem pelos imigrantes que já vinham para o Brasil desde fins do século XIX: "assim foi até o dia da avalanche italiana". Como mão de obra para o café, os italianos deslocam-se para o Oeste de São Paulo para trabalhar a "terra roxa", mas, já nos anos 20, "invadem o Brás" e os "espavoridos sapos sumiram-se aos pulos para as baixadas do Tietê" (LOBATO, 1993, p. 106).

O narrador descreve o início da formação do bairro em seus aspectos físicos e sociais tendo os italianos com seus hábitos culturais como agentes transformadores do espaço, pois as construções erguidas pareciam nada ter a ver com o ideário de modernização da cidade, nem com as construções brasileiras, já que as casas construídas com base nas "plantas de areia" e os locais de comércio eram edificados de acordo com padrões de construção e organização social próprios da Itália, o que modifica a paisagem natural (charco) daquela região e imprime uma nova paisagem, tão inusitada quanto a propiciada pelo Viaduto do Chá, o primeiro de São Paulo (erguido com estrutura de metal alemão, é inaugurado em 8/11/1892 e reformado em concreto em 1938).

A imagem da força do rápido crescimento da região é a de um monstro tentacular, que amplia a ideia da quantidade de imigrantes que formaram o Brás, imagem que Mário também verá em sua Pauliceia Desvairada:

E o Brás cresceu, espraiou-se de todos os lados, comeu todo o barro preto da Moóca, bateu estacas no Marco da Meia Légua, lançou-se rumo à Penha, pôs de pé igrejas, macadamizou ruas, inçou-se de fábricas, viu surgirem avenidas e vida própria, e cinemas, e o Colombo, e o namoro, e o corso pelo Carnaval. E lá está hoje [1920!] enorme, feito a cidade do Brás, separado de São Paulo pelo faixão vermelho da Várzea aterrada - Pest da Buda à beira do Tamanduateí plantada. (LOBATO, 1993, p. 106)

Além do aspecto físico do bairro, o narrador remete ao aspecto social dos novos habitantes de São Paulo, referidos na imagem de gente demais e aglomerada, que por fim será a própria imagem dessa cidade em todos os tempos: "ensardinham-se nos autos", "exuberante cacho humano", "o auto debulha-se do enxame", "bando", até chegar às metonímias em que os indivíduos se transfiguram no próprio bairro: “O Brás devora tudo” (LOBATO, 1993, p. 107). 
Mais que ficção, o conto alcança, com a ideia de progresso, ou daquilo que está começando e como está se formando, ser um registro da transformação. A cidade é configurada então pela margem e pela opulência do centro. No "Prólogo", tem-se o pântano, "com valas de agrião e rãs coaxantes" versus o parque do Anhangabaú, com "ruas de asfalto", e símbolos patrimoniais da classe dominante, como a escultura de "Eva de Brecheret, a estátua dum adolescente nu que corre", patrimônio móvel e metáfora da jovialidade da cidade e de sua pressa em crescer. Na parte do texto intitulada "Brás" há ainda outra oposição que marca o distanciamento desenvolvimentista: o charco e a várzea versus ladeiras como a da Boa Morte, do Carmo, do Piques, e ainda ruas do antigo - à época da enunciação - e importante centro comercial e financeiro da cidade de São Paulo, como a do Imperador, a Direita e São Bento.

A estruturação do conto, desde seu título, configura-se de modo circular, lembrando o círculo vicioso do progresso e da corrupção, começando pelo acontecimento do "Prólogo", ocorrido no centro "civilizadíssimo" da cidade e, seguindo para a oposição aos seus símbolos de modernidade, o narrador vai para a distante periferia na parte "Brás", registrando hábitos culturais, formas de lazer, socializações, disposição para o trabalho dos italianos. $\mathrm{Na}$ sequência, em "A vida", o narrador como que aproxima a câmera e focaliza a casa de uma família de italianos e seus membros e retrata sua dificuldade para sobreviver, recorrendo de novo à busca pelas origens para entender o processo. Narra então o nascimento da personagem causadora do "acontecimento", Pedrinho, no seio de uma família de italianos pobre; Por fim, no "Epílogo? Não! Primeiro ato...", o "Prólogo" tem sua sequência, quando se percebe a lógica dos subtítulos, que haviam remetido o leitor à forma do romance ou da novela, mas os fatos a serem tratados nessa parte levam o narrador a perceber nela um ato de uma peça teatral, tendo o espaço da cidade como o grande palco da tragédia que se descortinará. Assim, opta por "Primeiro ato", pois muitos outros dramas semelhantes viriam a acontecer com o crescente distanciamento das classes.

A modernidade dessa narrativa de Lobato está na escolha pelo urbano; na alusão aos patrimônios imóveis e móveis de sua cidade e dos patrimônios imateriais; na forma do conto, que questiona o gênero enquanto é criado e lhe confere novos contornos; na temática da imigração, que aponta para a decadência de uma classe de ricos cafeicultores e a ainda insipiente emergência de outra, a dos trabalhadores italianos; está na discussão do Brasil moderno 
versus o excluído dessa modernidade; no tratamento do assunto dessa narrativa curta como documento social; além de, quanto à linguagem, valer-se de metáforas e termos da biologia na caracterização de personagens, e ainda de jargões e outros traços da oralidade, valorizando outro patrimônio imaterial, as contribuições linguísticas.

Na contística produzida a partir do Modernismo, novos temas e novas formas vêm sendo experimentados, revelando o potencial criador de nossos escritores ao conferirem a esse gênero formas artísticas peculiares, assim como por buscarem representar expressões da identidade nacional e colaborar para o esforço da época de compreensão crítica do Brasil.

Alcântara Machado mostra-se "sensível à viragem da prosa ficcional, aplicando-se todo a renovar a estrutura e o andamento da história curta", como afirma Bosi (1996, p. 374). O título de seu livro de estreia, de 1927, já remete o leitor a bairros da cidade de São Paulo: Brás, Bexiga e Barra Funda (Notícias de São Paulo) e, como empreenderá o esforço para uma compreensão crítica do Brasil pela parte, também preocupações políticas comporão seu texto cujo cenário é o de bairros periféricos ao centro da cidade.

Como fixador de tipos, o autor cria personagens que revelam o "complexo ético-social do proletariado e do pequeno comércio ítalo-brasileiro", em busca da personagem coletiva (RIEDEL, 1969, p. 270). O imaginário que se constrói após a leitura de seus contos sobre o imigrante italiano, como o de trabalhador incansável, ambicioso, alegre e bem falante, revela esse coletivo e um importante patrimônio imaterial da cidade.

As ações do conto desenvolvem-se, preferencialmente, na rua - e não dentro das casas - da periferia da São Paulo em pleno crescimento, e nesse espaço de fora há o encontro das diferenças, onde as pessoas convivem ou conflitam na nova terra. Essas imagens são captadas do cotidiano ou de seus flagrantes e, acompanhando o desenvolvimento da imprensa, seus contos nascem como notícias de jornal em frases e jargões, a que até o subtítulo do livro remete: "Notícias de São Paulo", de modo que parecem mesmo imitar procedimentos do jornal, privilegiando a informação, em que os fatos se armam em sequências historiadas, mas dando-lhe tratos humanizados até esgotarem-se no desfecho.

As representações do sistema capitalista na prática estão por todos os contos de Alcântara, como em "Armazém Progresso de São Paulo", no qual o comerciante italiano é retratado em seu local de trabalho a exercer seu ofício. Natale 
representa a classe média em formação; seus negócios estão se expandindo, "começou com uma porta no lado par da Rua da Abolição. Agora tinha quatro no lado ímpar", mas não era por acaso que enriquecia: "não despregava do balcão de madrugada a madrugada. Trabalhava como um danado. E Dona Bianca suando firme na cozinha e no bocce" (MACHADO, 1996, p. 49-50). Observe-se que o narrador registra essa prática desportiva e de socialização bastante presente no início do século XX, quando certos comércios ofereciam esse jogo nos fundos das instalações, desempenhando uma função também social, por funcionarem como ponto de encontro para longas conversas e partidas de baralho, assim como de exercício de traços culturais que foram sendo aos poucos abandonados e hoje aquele espaço de resistência cultural foi deslocado para clubes. Esse jogo é patrimônio imaterial e ainda instrumento identitário na cidade.

Desde o início do conto Natale mostra-se disposto a qualquer coisa para ganhar dinheiro e continuar subindo na vida. O narrador reforça a imagem do comerciante habilidoso para os negócios ao descrever sua próxima vítima com traços de afetividade revelados na escolha vocabular: "Em frente a Confeitaria Paiva Couceiro expunha renques de cebola e a mulher do proprietário grávida com um filhinho no colo" (1996, p. 50). Observe-se que a construção frasal e sua pontuação permitem equivaler à imagem dos renques de cebola aos da mulher com um filho no colo e outro na barriga, expostos na confeitaria em frente ao comércio de Natale como mercadorias aos olhos deste, que intenta comprar-lhe as cebolas a preço baixíssimo, pois obteve de um assíduo freguês, "José Espiridião, o mulato, o do Abastecimento, ora, da Comissão do Abastecimento" (1996, p. 51), a informação privilegiada de que "A tabela vai subir porque a colheita foi fracota como o diabo". E, ampliando a ironia, o sr. José exclama com hipocrisia: "Ai, ai! Coitado de quem é pobre" (1996, p. 51). Essa frase também revela ambiguidade, pois se refere ao padeiro em frente, mas também funciona como sinal de alerta para o italiano, que pode perder tudo, o que o apavora e o leva a tomar a atitude de quebrar o outro antes que isso possa acontecer a ele mesmo. Assim, trabalho, concorrência, corrupção são enfocados nos contos como inerentes ao mundo capitalista, mas com custos sociais altos, como o escritor denuncia em sua escolha temática.

Alcântara Machado escolhe observar sua cidade pelo mundo do trabalho e comércio, voltando seu olhar para o patrimônio imaterial da cidade, para as pessoas que movimentam no microcosmo a gigante cidade. Lega por suas 
escolhas registros ficcionais de uma sociedade se configurando como do trabalho, cuja metáfora é a da cidade como um grande armazém, ou "Armazém Progresso de São Paulo”, pois o progresso da cidade deu-se, tantas vezes, pelo sucesso de uns em face da derrocada de outros.

Contos novos (1980) revela a maturidade artística de Mário de Andrade, com textos mais depurados estilisticamente. Neles, conquistas dos modernistas estão presentes, assim como as principais correntes da ficção brasileira das décadas de 30 e 40, com o registro do íntimo das personagens pela técnica do fluxo de pensamento, o que lhe permite uma sondagem psicológica dessas personagens.

No conto "Primeiro de Maio", escrito de 1934-1942, desse livro que foi publicado post mortem em 1947, até no feriado do dia do trabalhador se trabalha, de modo que a imagem do paulista como povo trabalhador configurase como patrimônio imaterial da cidade, ao lado dos patrimônios móveis e imóveis, como seus símbolos de crescimento, suas praças, jardins, os quais contam a história do lugar, como a Estação da Luz. Inaugurada em 1867 e construída pela "inglesa" The São Paulo Railway, fazia a linha Jundiaí-Santos, de onde o café era exportado, tornando-se símbolo de seu ciclo. Foi reformada para ampliação com material importado da Europa e reinaugurada em 1901. Mário alude a essa Estação já ampliada e usada também como meio de deslocamento das pessoas do interior para a capital. Também é referida na caminhada do "chapinha 35" a Estação do Norte, inaugurada em 1875, passando depois a chamar-se Estação Roosevelt, a qual foi símbolo da pujança de grandes fazendeiros do café do Vale do Paraíba, que a construíram, mas que decretaram a falência das demais cidades cafeicultoras que ficaram fora das linhas do trem. Assim como a Estação da Lur, a do Norte servia como meio de transporte de pessoas do interior para a capital, ou de outras regiões, como a do norte: "Mais cabeça-chata, o 35 imaginou com muita aceitação" (1980, p. 48). Na busca de descansar, o 35 prefere o Jardim da Luz ao Jardim do Anhangabaú, já que este era símbolo da elite. Outro ponto que é referência de grandes momentos históricos da cidade e do país é o Largo da Sé, onde poderia haver "motins de-tarde". O Palácio das Indústrias é o local permitido para as comemorações do dia do trabalho, mas, assim como o Jardim do Anhangabaú, é símbolo da classe dos patrões e lá o 35 não vê operários.

A alusão à "esplêndida macarronada", às "duas médias" que toma em um dos cafés do bairro com "pão com bastante manteiga”, revela hábitos alimen- 
tares mantidos pelo paulista, que são marca da influência italiana e do encontro das pessoas nos cafés, sendo também registro de patrimônios imateriais.

Os símbolos do mundo do trabalho, os lugares do lazer, os pontos cruciais da cidade do paulistano ganham visibilidade na caminhada do trabalhador, o "35", recurso estilístico que desconstrói a individualidade, mas, ao mesmo tempo, lança luz sobre um trabalhador em seu dia e, pela sensibilidade e criatividade do escritor, passa a ter uma existência particular, pois é patrimônio imaterial que faz São Paulo ser a metrópole que é. Essa sensibilidade do olhar do escritor dá existência aos trabalhadores do microcosmo, patrimônio imaterial da cidade, e ilumina os patrimônios imóveis.

Críticos literários cogitam sobre a referência de Mário aos trabalhadores por números: 35 seria uma alusão ao ano em que foi decretado o feriado de Primeiro de Maio e 22 faria lembrar a data de fundação do Partido Comunista Brasileiro. Entretanto, como em 1935 Mário assume a direção do Departamento Municipal de Cultura da cidade de São Paulo, e como consta de documentos sua preocupação com os patrimônios móveis, imóveis e imateriais dessa cidade e do Brasil, alguns dos quais são referidos na caminhada de “35”, é possível se cogitar em outras simbologias para essa identificação de personagens por números, remetendo o 22 à Semana de 22 e seu projeto de independência cultural do Brasil.

Os momentos captados e selecionados pelo olhar atento do escritor podem reconstituir uma imagem de um momento do microcosmo da metrópole, que permite ao leitor contemporâneo a sensação de pertencimento, pois a ideia de que tudo é um processo está presente, já que muitos de seus patrimônios estão preservados.

\section{Referência Bibliográfica}

ANDRADE, Mário. Primeiro de Maio. Contos novos. 10a . ed. São Paulo: Martins ; Belo Horizonte: Itatiaia, 1980, p. 35-48.

Bergson, Henry. Matéria e memória - ensaio sobre a relação do corpo com o espírito. Trad. Paulo Neves. São Paulo: Martins Fontes, 1990.

Bosi, Alfredo. História concisa da literatura brasileira. 34ª . ed. São Paulo: Cultrix, 1996.

CORTÁZAR, Julio. Alguns aspectos do conto. Valise de Cronópio. São Paulo: Perspectiva, 1974 , p. $147-163$. 
LOBATO, Monteiro. O fisco. Contos escolbidos. Lajolo, Marisa (org.). $3^{\text {a }}$. ed. São Paulo: Brasiliense, 1993, p. 103-13.

MACHADO, A. Alcântara. Armazém Progresso de São Paulo. Brás, Bexiga e Barra Funda \& Laranja-da-China. Rio de Janeiro: Artium, 1996, p. 49-52.

Marx, Karl. Manuscritos econômicos e filosóficos. In: Oeuvres. tomo III. Paris: 1968, (Mega).

Revista do Patrimônio Histórico e Artístico Nacional, n. 30, Rio de Janeiro: SPHAN/ PróMemória, 2002.

RIEDEL, Dirce C. O modernismo na ficção. Experimentalismo. In: COUTINHO, Afrânio; COUTINHO, Eduardo de F. (orgs.). A literatura no Brasil. Rio de Janeiro: Ed. Sul-Americana, 1969, v.5. 